\title{
PNEUMOCANDIN $D_{0}$, A NEW ANTIFUNGAL AGENT AND POTENT INHIBITOR OF Pneumocystis carinii
}

\author{
Sandra A. Morris*, Robert E. Schwartz, David F. Sesin, Prakash Masurekar, \\ Thomas C. Hallada, Dennis M. Schmatz, Kenneth Bartizal, \\ Otto D. Hensens and Deborah L. Zink
}

Merck Research Laboratories,

P. O. Box 2000 (R80Y-340) Rahway, N. J. 07065-0900, U.S.A.

(Received for publication February 3, 1994)

\begin{abstract}
Pneumocandin $\mathrm{D}_{0}(9)$, a new member of the echinocandin class of antifungal agents, has been isolated as a minor constituent from fermentation broths of the filamentous fungi Zalerion arboricola (ATCC 20957). The structure of 9 has been determined mainly on the basis of spectroscopic analysis and by comparison with published data for similar compounds. To date, pneumocandin $\mathrm{D}_{0}$ has been found to be the most potent inhibitor of Pneumocystis carinii development in vivo within the natural-occuring echinocandin family of antifungal agents.
\end{abstract}

Aculeacin ${ }^{1,2)}$ and echinocandin $\mathrm{B}^{3,4)}$ are two representatives of a large class of naturally-occurring antifungal lipopeptides, the echinocandins, which are characterized by potent fungicidal activity against Candida spp. ${ }^{5,6)}$ In the search for new antifungal agents, a series of compounds belonging to this same

Fig. 1. Structures of pneumocandins $A_{0}, A_{1}, A_{2}, A_{3}, A_{4}, B_{0}, B_{2}$ and $C_{0}$.

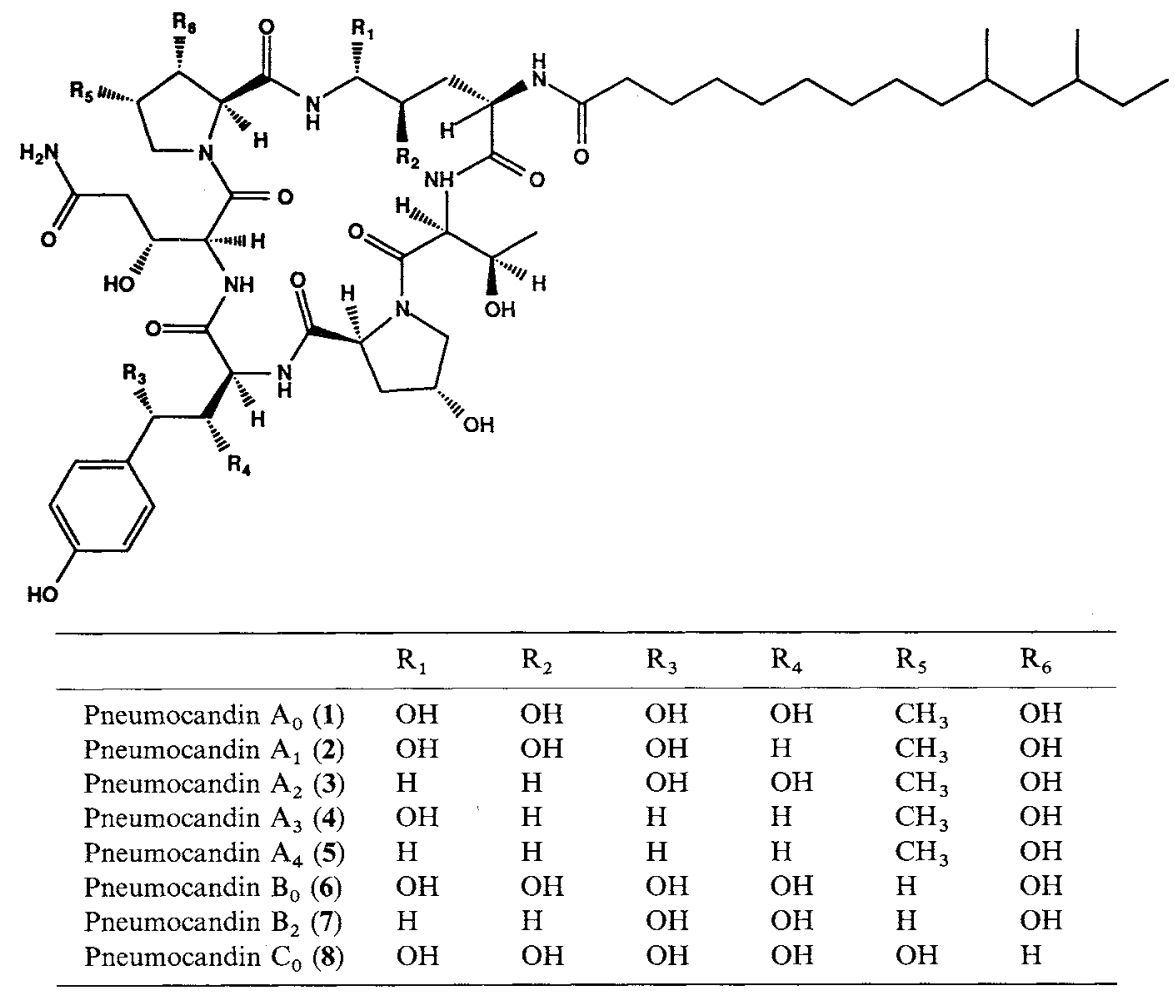


Fig. 2. Structure of pneumocandin $\mathrm{D}_{0}(9)$.

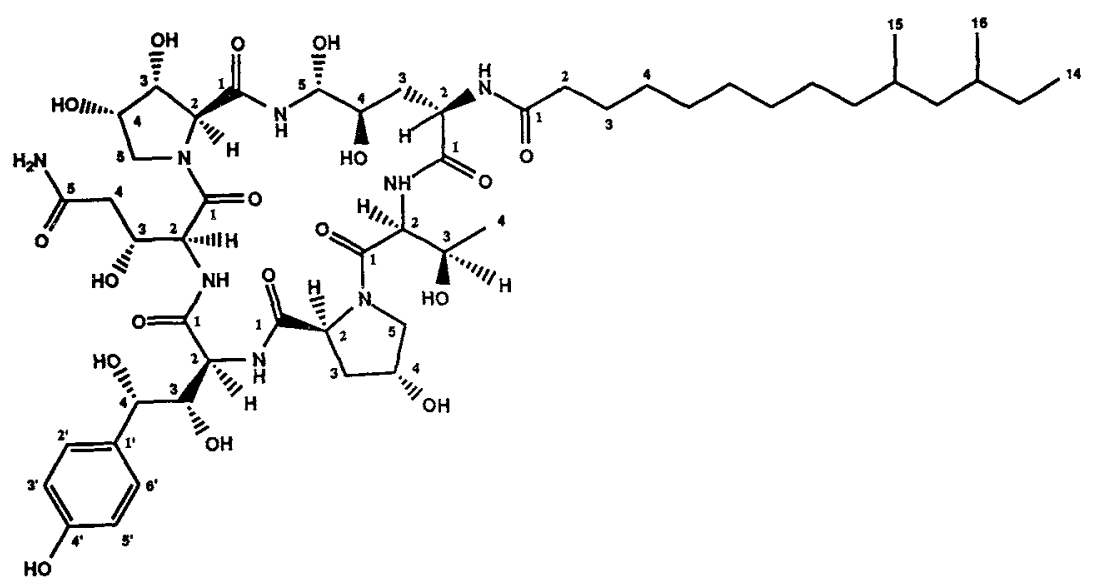

class, the pneumocandins $\left(A_{0} \sim A_{4}, B_{0}, B_{2}\right.$ and $\left.C_{0} ; 1 \sim 8\right)$ (Fig. 1), has recently been isolated from fermentation broths of the filamentous fungi Zalerion arboricola (ATCC 20957) by researchers from these laboratories. ${ }^{72)}$ As well as possessing considerable activity against Candida spp., the pneumocandins have also been shown to have considerable potency against Pneumocystis carinii, the causative agent of life-threatening pneumonia in immunocompromised patients. ${ }^{13,14)}$ The mode of action against these organisms is believed to be via inhibition of the synthesis of 1,3- $\beta$-D-glucan, a fungal cell wall component. ${ }^{13,14)}$ We wish to now report on the fermentation, isolation, structure determination and biological activity of pneumocandin $\mathrm{D}_{0}(\mathbf{9}$, Fig. 2), a minor metabolite isolated from fermentation broths of $Z$. arboricola. The structure determination of 9 was based primarily on analysis of spectroscopic data and comparison of the data with that previously reported for the other pneumocandins. Pneumocandin $\mathrm{D}_{0}$ displays considerable potency in vivo against systemic candidiasis, the level of potency being comparable with those observed for other members within the family of naturally-occuring pneumocandins. However, within the family, $D_{0}$ is the most potent in vivo inhibitor of $P$. carinii infections isolated to date.

\section{Materials and Methods}

Producing Strain

Z. arboricola (ATCC 20957) was produced by chemically induced mutation of strain ATCC 20868 as described by MaSUREKAR et al. (1992). ${ }^{11}$

Fermentation of Zalerion arboricola (ATCC 20957) for the Production of Pneumocandin $D_{0}$ Fermentation of Z. arboricola (ATCC 20957) was carried out as described by SCHWARTZ et al. (1992). ${ }^{10}$

Isolation and Purification of Pneumocandin $\mathrm{D}_{0}(\mathbf{9})$

The $\mathrm{MeOH}$ extract of the whole broth from a large scale fermentation of $Z$. arboricola (ATCC 20957) (1.5: 1 whole broth - $\mathrm{MeOH}$ ratio; 10,750 liters whole broth in total) was centrifuged, adjusted with water to less than $50 \% \mathrm{MeOH}$ (Karl Fischer analysis) and adsorbed onto a fluidized bed of SP-207 (600 liters) in an upflow direction. The resin was washed with $\mathrm{MeOH}-\mathrm{H}_{2} \mathrm{O}(65: 35)$ and pneumocandin $\mathrm{D}_{0}(9)$ was eluted using $100 \% \mathrm{MeOH}$. Fractions containing pneumocandin $\mathrm{D}_{0}$ were identified by HPLC analysis (Phenomenex RP-C18; 50:50 $\mathrm{CH}_{3} \mathrm{CN}-0.01 \mathrm{M}$ potassium phosphate buffer, $\mathrm{pH}$ 7), combined, diluted with water to less than $50 \% \mathrm{MeOH}$ (Karl Fischer analysis) and passed downflow through a bed of HP-20 (140 liters) in order to again adsorb 9 . The resin was washed with $\mathrm{H}_{2} \mathrm{O}-\mathrm{MeOH}(65: 35)$ and the active component 
was eluted with $100 \% \mathrm{MeOH}$. An additional SP-207 adsorption/elution step was performed next to further concentrate the material and reduce the $\mathrm{H}_{2} \mathrm{O}$ content.

Separation of pneumocandin $\mathrm{D}_{0}$ from the more non-polar components in the methanolic SP-207 rich cut (primarily the antifoam P-2000 used in the fermentation) was accomplished via precipitation with isopropyl acetate. The combined SP-207 fractions $(500 \mathrm{ml})$ were slowly added to ten volumes of isopropyl acetate at $25^{\circ} \mathrm{C}$. The precipitate, which contained the compound of interest, was filtered, dried under vacuum (total solids $=4.8 \mathrm{~kg}$ ) and dissolved in $550 \mathrm{ml}$ of EtOAc $-\mathrm{MeOH}-5 \%$ aq AcOH $(2: 2: 1)$. Portions of this sample were diluted to a final solvent composition of EtOAc-MeOH - 5\% aq AcOH $(76: 16: 8)$ prior to silica gel HPLC chromatography.

A $700 \mathrm{ml}$ aliquot of this preparation $(2.44 \mathrm{~kg}$ total solids) was chromatographed on a preparative silica HPLC column (5.8 liters of Matrex irregular silica; $20 \mathrm{~mm}$ particle size; $60 \AA$ pore size; Amicon, Danvers, MA) utilizing EtOAc- $\mathrm{MeOH}-5 \%$ aq AcOH $(85: 10: 5)$ as the mobile phase. The column was run at a flow rate of $605 \mathrm{ml} /$ minute and fractions of 1.75 liters were collected. Fractions containing pneumocandin $\mathrm{D}_{0}$ were identified via HPLC analysis (Zorbax-Si; $80: 20: 2 \mathrm{CH}_{2} \mathrm{Cl}_{2}-\mathrm{MeOH}-\mathrm{H}_{2} \mathrm{O}$ ).

Fraction 18 from the preparative silica HPLC run was concentrated in vacuo to yield $1.4 \mathrm{~g}$ of total solids. The material was then reconstituted in $20 \mathrm{ml}$ of $\mathrm{CH}_{2} \mathrm{Cl}_{2}-\mathrm{MeOH}-\mathrm{H}_{2} \mathrm{O}(80: 20: 2)$, filtered through a $5 \mathrm{~mm}$ syringe filter and purified via semi-preparative normal phase HPLC $(10 \times 2 \mathrm{ml}$ injections; Whatman Partisil 10, $21.2 \mathrm{~mm}$ i.d. $\times 50 \mathrm{~cm}$ silica gel column) using $\mathrm{CH}_{2} \mathrm{Cl}_{2}-\mathrm{MeOH}-\mathrm{H}_{2} \mathrm{O}(80: 20: 2)$ as the mobile phase. Fractions containing pneumocandin $\mathrm{D}_{0}$, as evidenced by analytical HPLC analysis of the fractions (Zorbax-Si; 80:20:2 $\mathrm{CH}_{2} \mathrm{Cl}_{2}-\mathrm{MeOH}-\mathrm{H}_{2} \mathrm{O}$ ), were combined, concentrated, reconstituted in $200 \mathrm{ml}$ $\mathrm{H}_{2} \mathrm{O}-\mathrm{MeOH}(50: 50)$ and adsorbed onto a $50 \mathrm{ml} \mathrm{HP}-20$ column. The column was washed with $\mathrm{H}_{2} \mathrm{O}-\mathrm{MeOH}$ (50:50) and then eluted with $100 \% \mathrm{MeOH}$ to yield $235 \mathrm{mg}$ of pure pneumocandin $\mathrm{D}_{0}$ as a white powder upon drying.

\section{Spectroscopic Methods}

All NMR spectra were recorded on a Varian UNITY 400 spectrometer at ambient temperature in $\mathrm{CD}_{3} \mathrm{OD}$. The ${ }^{1} \mathrm{H}$ NMR data listed in Table 1 were recorded at $400 \mathrm{MHz}$ in $\mathrm{CD}_{3} \mathrm{OD}$ using the solvent peak at $\delta 3.30$ as internal reference. The ${ }^{13} \mathrm{C}$ NMR data in Table 1 were recorded at $100 \mathrm{MHz}$ in $\mathrm{CD}_{3} \mathrm{OD}$; the chemical shifts are given in ppm downfield of TMS using the solvent peak at $49.0 \mathrm{ppm}$ as internal reference. The selective 1D-HMBC ( ${ }^{1} \mathrm{H}$-detected multiple-bond heteronuclear multiple-quantum coherence) experiment (SIMBA) (selective inverse multiple bond analysis) ${ }^{15}$ was carried out by application of a soft gaussian excitation pulse to the carbonyl at $169.4 \mathrm{ppm}$; six different experiments, optimizing for $J_{\mathrm{c}-\mathrm{H}}=2,3,4,5,6$ and $7 \mathrm{~Hz}$, were carried out and the resulting proton enhancements were observed in each case. A series of ROESY (rotating frame overhauser effect spectroscopy) spectra were recorded with mixing times of $50,100,150,200$ and $300 \mathrm{~ms}$.

The UV absorption spectrum was measured with a Beckman DU-70 instrument affording UV $\lambda_{\max }^{\mathrm{MeOH}} \mathrm{nm}\left(\mathrm{E}_{1 \mathrm{~cm}}^{1 \%}\right) 204(751), 225(\mathrm{sh}, 395)$ and $276(42)$. The IR absorption spectrum was obtained with a Perkin-Elmer model 1750 instrument using a multiple internal reflectance cell (MIR, ZnSe) affording IR (neat) 3315 (br), 2929, 1631, 1540, 1455, 1232 and $1066 \mathrm{~cm}^{-1}$.

Electron impact (EI) mass spectral data were obtained on either a Finnigan-MAT 212 mass spectrometer at $90 \mathrm{eV}$ or a Finnigan-MAT TSQ70 at $70 \mathrm{eV}$. Fast atom bombardment (FAB) mass spectra were recorded on a JEOL HX110A instrument using dithioerythritol/dithioerythreitol. Samples were hydrolyzed in $6 \mathrm{~N} \mathrm{HCl}$ in tightly capped vials at $110^{\circ} \mathrm{C}$ for 18 hours and then evaporated to dryness under a stream of nitrogen. The hydrolysate residue was derivatized with a $1: 1$ mixture of BSTFA (bis(trimethylsilyl)trifluoroacetamide) (or BSTFA- $d_{9}$ ) and pyridine at $50^{\circ} \mathrm{C}$ for 30 minutes. GC-MS analyses were carried out using a J \& W DB-5 Durabond capillary column $(15 \mathrm{~m} \times 0.3 \mathrm{~mm}, 25 \mathrm{~mm}$ film). Components were identified by interpretation of their mass spectra and by comparison to library spectra.

\section{Absolute Stereochemistry}

To determine the absolute configuration of threonine in pneumocandin $\mathrm{D}_{0}$, a sample was first hydrolyzed in $6 \mathrm{~N} \mathrm{HCl}$ at $110^{\circ} \mathrm{C}$ for 18 hours. After evaporation of the hydrolysate, the $(R)$ - $\alpha$-methylbenzylisothiocyanate (AMBI) derivatives were prepared as previously described ${ }^{16)}$ and another portion silylated for GC-MS analysis. The AMBI derivatives were separated on an ABI 130-A HPLC 
system equipped with a Spheri-5RP-18 $220 \times 2.1 \mathrm{~mm}$ column and the components detected at $254 \mathrm{~nm}$. The mobile phases consisted of: A, $60 \%$ aqueous ammonium acetate buffer $(0.14 \mathrm{M}$, with $0.05 \%$ triethylamine adjusted to $\mathrm{pH} 6.40$ with acetic acid) and $40 \%$ acetonitrile; $\mathrm{B}, 60 \%$ acetonitrile. The following gradients were used: $10 \%$ B for 4 minutes, $40 \% \mathrm{~B}$ at 30 minutes, $100 \% \mathrm{~B}$ at 35 minutes and held for 5 minutes at a flow rate of $250 \mu \mathrm{l} /$ minute and an oven temperature of $26^{\circ} \mathrm{C}$. GC-MS analysis confirmed the presence of threonine, whereas, the HPLC analysis of the AMBI derivatives indicated its stereochemistry as L-threonine from its retention time by comparison with authentic samples.

\section{Broth Microdilution Assay for Minimum Fungicidal Determinations}

Compounds were evaluated against a selected panel of clinically relevant fungi for the determination of antifungal spectrum and potency. Broth microdilution methodology was employed to determine minimum fungicidal concentrations (MFC) as described previously. ${ }^{17)}$ MFC values were determined by removing aliquots from each well and plating them on compound-free agar medium and defined as the lowest concentration of compound showing less than 4 colonies.

\section{Glucan Synthesis Inhibition Assay}

Buffer A: $10 \%$ glycerol (1.2 M) in phosphate buffered saline (PBS) containing phenylmethylsulfonyl fluoride (PMSF; $0.5 \mathrm{~mm}$ ) and DTT (1 mM). Buffer B: buffer A without PMSF and DTT. Buffer C: Dulbeccos's PBS, pH 7.0 (Gibco, Grand Island, NY) containing EDTA (5mM) and DTT (50 mm). Alpha-amylase stock solution: The enzyme was obtained from Sigma Chemical Co., St. Louis, MO, supplied as a suspension in ammonium sulfate. This suspension $(10 \mu 1,0.24 \mathrm{mg}$ protein, equivalent to 264 units) was diluted with $115 \mu \mathrm{l}$ buffer $\mathrm{B}$. UDP-[6- $\left.{ }^{3} \mathrm{H}\right]$-glucose was obtained from Amersham Radiochemicals, Arlington Heights, IL, supplied at $250 \mu \mathrm{Ci} / 250 \mu \mathrm{l}(14.7 \mathrm{Ci} / \mathrm{mmol}) ; 5 \mu \mathrm{l}$ of a $1: 5$ dilution $(500,000 \mathrm{dpm})$ is equivalent to 77 pmoles. GTP- $\gamma-\mathrm{S}$ was obtained from Sigma.

Candida albicans (MY-1208) cells were grown to early log phase ( $6 \sim 8$ hours) in $500 \mathrm{ml}$ of Sabouraud dextrose broth (Difco) in a 2-liter baffled shake flask at $28^{\circ} \mathrm{C}$ at $150 \mathrm{rpm}$. The membrane-associated synthase system was prepared from protoplasts essentially by the method of TAFT et al. ${ }^{18)}$ The assay of ${ }^{3} \mathrm{H}$-glucan was coducted as a modification of the method previously described by CABIB and KANG for Saccharomyces cerevisiae. ${ }^{19)}$ The total volume in wells of a microtiter plate designed for automated collection of the products of synthesis was $80 \mu$ l. The incubation system contained $6.6 \%$ DMSO, $125 \mathrm{mM}$ Tris- $\mathrm{HCl}(\mathrm{pH}$ 7.5), 0.25 mM DTT, 0.15 mm PMSF, 0.4 M glycerol, 0.75 mM EDTA, 0.25\% BSA, $40 \mathrm{~mm}$ GTP- $\gamma-\mathrm{S}, 2.5 \mathrm{~mm}$ laminaribiose, 30 units/system of $\alpha$-amylase, synthase ( $500 \mu \mathrm{g}$ protein $/ \mathrm{ml}$ assay system) contained in $15 \mu 1$ and $25 \mu \mathrm{M}$ UDPG, the required concentration added in $10 \mu 1$ including UDP- $\left[6-{ }^{3} \mathrm{H}\right]$-glucose $(500,000 \mathrm{dpm})$. To determine the inhibitory effect of analogs, samples were added at $1.5 \mathrm{~mm}$ and serially diluted to a level of $0.04 \mu \mathrm{M}$. Compounds for evaluation were contained in $4 \mu \mathrm{l}$ of $50 \%$ DMSO. During the assay, the microtiter plates were covered with Parafilm and incubated for 60 minutes at $24^{\circ} \mathrm{C}$ with agitation on a Minimix stand (Fischer Scientific). The reaction was terminated by the addition of TCA $(10 \%, 100 \mathrm{ml} /$ well $)$ and the resulting insoluble materials were collected on a glass fiber filter mat in a Wallac (LKB) cell harvester, followed by automated wash cycles (water and $95 \%$ ethanol). The incorporated radiolabel per well was determined in a model 1205 Betaplate liquid scintillation counter (LKB, Wallac). The 1,3- $\beta$-D-glucan synthesis inhibitory concentration $\left(\mathrm{IC}_{50}\right)$ was defined as the concentration at which a compound inhibited $50 \%$ of the production of acid precipitable product.

\section{Red Blood Cell (RBC) Lysis Assay}

A 4\% suspension of freshly-drawn whole heparinized human or CD-1 mouse blood was prepared by adding $2.0 \mathrm{ml}$ of blood to $50 \mathrm{ml}$ of sterile $5 \%$ glucose. Compounds were solubilized in $10 \%$ DMSO at a concentration of $4.0 \mathrm{mg} / \mathrm{ml}$ and further diluted to a concentration of $0.5 \mu \mathrm{g} / \mathrm{ml}$ by the addition of sterile $5 \%$ dextrose. Test compounds were dispensed into wells of microtiter plates and serially two-fold diluted in $5 \%$ glucose and then $38 \mu \mathrm{l}$ of $\mathrm{RBC}$ suspension were added to each well to yield final test concentrations of 400 to $0.20 \mu \mathrm{g} / \mathrm{ml}$. Plates were mixed gently and incubated at room temperature and results were determined after 2 hours of incubation. Hemolysis of erythrocytes was indicated by complete or partial clearing (lysis). Minimum lytic concentration (MLC) was defined as the lowest concentration of a test compound which produced complete or partial lysis of erythrocytes. 
The Target Organ Kidney Assay (TOKA) Evaluation of In Vivo Efficacy against Candida albicans

The target organ kidney assay used for evaluation of antifungal efficacy against $C$. albicans has been described in detail previously. ${ }^{17)}$ Briefly, C. albicans MY 1055 was administered intravenously in the tail veins of DBA/2 mice, at an inoculum of $7.5 \times 10^{4}$ cells/mouse. Pneumocandins were solubilized in $10 \%$ DMSO and tested at various concentrations ranging from 1.25 to $10 \mathrm{mg} / \mathrm{kg}$ intraperitoneally, twice-daily (b.i.d.) for 4 consecutive days. Five mice per group were sacrificed at 7 days after initiation of infection for determination of $C$. albicans colony forming units (CFU) per gram kidneys. Effective dose $90 \%\left(\mathrm{ED}_{90}\right)$ estimates were derived to rank efficacy. The range of variability in the TOKA is within a two-fold dilution range around the $\mathrm{ED}_{90}$ value.

Rat Acute Pneumocystis carinii Pneumonia (PCP) Model-Evaluation of In Vivo Efficacy against Pneumocystis carinii (PCP assay)

The dexamethasone immunosuppressed rat model used in these studies has been described in detail elsewhere. ${ }^{13)}$ To evaluate the efficacy of the compounds in this model, rats immunosuppressed for six weeks were treated intraperitoneally or subcutaneously, b.i.d., for four days. All compounds were solubilized in $10 \%$ DMSO and injected in a $0.5 \mathrm{ml}$ volume. Compounds were tested at the appropriate levels to establish an $\mathrm{ED}_{90}$. Each test group contained 6 rats. On the morning following the last dose, rats were sacrificed and their lungs were removed and processed according to the procedure outlined previously. ${ }^{13}$ )

\section{Results and Discussion}

\section{Structure Determination}

For convenience, both the residue positions in pneumocandin $D_{0}$ and the numbering of the protons and carbons within the residues will be referred to in a similar manner as those in pneumocandin $\mathrm{A}_{0}{ }^{8}$ ) This has been used as the convention for all of the pneumocandins isolated to date. ${ }^{12)}$ The residues present in pneumocandin $\mathrm{D}_{0}$ are: 4,5-dihydroxyornithine (DiOHOrn), 3,4-dihydroxyproline (DiOHPro), 3-hydroxyglutamine (3-OHGIn), 3,4-dihydroxyhomotyrosine (DiOHTyr), 4-hydroxyproline (4-OHPro), threonine (Thr) and 10,12-dimethylmyristate (DMM).

High resolution FAB-MS suggested a molecular formula of $\mathrm{C}_{50} \mathrm{H}_{80} \mathrm{~N}_{8} \mathrm{O}_{18}$ for pneumocandin $\mathrm{D}_{0}$ ( $m / z$ found: $1103.5460 ; m / z$ calcd: 1103.5488 for a formula of $\mathrm{C}_{50} \mathrm{H}_{80} \mathrm{~N}_{8} \mathrm{O}_{18} \mathrm{Na},[\mathrm{M}+\mathrm{Na}]^{+}$), a formula which differs from that of pneumocandin $\mathrm{B}_{0}(6)\left(\mathrm{C}_{50} \mathrm{H}_{80} \mathrm{~N}_{8} \mathrm{O}_{17}\right)^{12)}$ by a single oxygen atom. Consistent with the MS data, the ${ }^{13} \mathrm{C}$ NMR spectrum of 9 indicated the presence of 50 carbons (Table 1). A DEPT experiment revealed that 62 of the protons in 9 were attached to carbons, inferring the presence of 18 exchangeable protons, one more than in pneumocandin $\mathrm{B}_{0}$. The ${ }^{13} \mathrm{C}$ and DEPT spectra for 9 showed nine oxygenated carbon doublets, one more than in 6 . The extra oxygenated carbon doublet $(\delta 71.9 \mathrm{ppm})$ replaces a carbon triplet at $\delta 34.8 \mathrm{ppm}$ in pneumocandin $\mathrm{B}_{0}$ (Table 1), a resonance belonging to the 3-OHPro residue in 6. Except for those resonances belonging to the 3-OHPro residue, all of the ${ }^{13} \mathrm{C}$ resonances assigned to the carbons in pneumocandin $B_{0}$ matched the resonances in the ${ }^{13} \mathrm{C}$ NMR spectrum of pneumocandin $\mathrm{D}_{0}$ within $0.4 \mathrm{ppm}$ (Table 1). Based upon the differences in both the molecular formulae and the ${ }^{13} \mathrm{C}$ NMR and DEPT spectra of pneumocandins $\mathrm{D}_{0}$ and $\mathrm{B}_{0}$, it was concluded that the two compounds differed in structure by replacement of the 3-OHPro residue in $\mathbf{B}_{0}$ with a dihydroxylated proline residue in $\mathrm{D}_{0}$. This conclusion was corroborated by GC-MS analysis of the TMS derivatives of the total acid hydrolysate of 9 which yielded 5 major components: Thr, 4-OHPro, 3-OHGln, DiOHPro and a 16:0 fatty acid. The DiOHOrn and DiOHTyr residues do not survive the acid treatment. ${ }^{8)}$ Assignment of the identity of the new amino acid residue in pneumocandin $D_{0}$ as 3,4-dihydroxyproline and confirmation of the identities of the five other amino acid residues and the fatty acid side chain came from careful 
Table 1. ${ }^{1} \mathrm{H}(400 \mathrm{MHz}) \mathrm{NMR}$ data for pneumocandin $\mathrm{D}_{0}(9)$ and ${ }^{13} \mathrm{C}(100 \mathrm{MHz}) \mathrm{NMR}$ data for pneumocandins $\mathrm{D}_{0}(9)$ and $\mathrm{B}_{0}(6){ }^{\mathrm{a}, \mathrm{b}}$

\begin{tabular}{|c|c|c|c|c|c|c|c|}
\hline Assignment & $\begin{array}{c}{ }^{1} \mathrm{H}(\mathrm{ppm}) \\
(9)\end{array}$ & $\begin{array}{c}{ }^{13} \mathrm{C}(\mathrm{ppm}) \\
(9)\end{array}$ & $\begin{array}{c}{ }^{13} \mathrm{C}(\mathrm{ppm}) \\
(6)\end{array}$ & Assignment & $\begin{array}{c}{ }^{1} \mathrm{H}(\mathrm{ppm}) \\
(\mathbf{9})\end{array}$ & ${ }_{(9)}^{13} \mathrm{C}(\mathrm{ppm})$ & $\begin{array}{c}{ }^{13} \mathrm{C}(\mathrm{ppm}) \\
(6)\end{array}$ \\
\hline \multicolumn{4}{|c|}{ 3,4-Dihydroxyhomotyrosine (DiOHTyr) } & \multicolumn{4}{|c|}{ 10,12-Dimethylmyristate (DMM) } \\
\hline $\mathrm{C}-1$ & - & $172.6(\mathrm{~s})$ & $172.5(\mathrm{~s})$ & C-1 & - & $175.8(\mathrm{~s})$ & $175.8(\mathrm{~s})$ \\
\hline $\mathrm{C}-2$ & $4.31(\mathrm{~d} ; 1.5)$ & $56.3(\mathrm{~d})$ & $56.3(\mathrm{~d})$ & $\mathrm{C}-2$ & $2.22(\mathrm{t} ; 7.0)$ & $36.7(t)$ & $36.7(t)$ \\
\hline $\mathrm{C}-3$ & $4.26(\mathrm{~m})$ & $76.9(\mathrm{~d})$ & 76.9 (d) & $\mathrm{C}-3$ & $1.58(\mathrm{~m})$ & $27.0(t)$ & $27.0(\mathrm{t})$ \\
\hline $\mathrm{C}-4$ & $4.27(\mathrm{~m})$ & $75.8(d)$ & $75.8(\mathrm{~d})$ & $\mathrm{C}-4$ & $1.28(\mathrm{~m})$ & $30.31(t)$ & $30.30(t)$ \\
\hline $\mathrm{C}-1^{\prime}$ & - & $133.0(\mathrm{~s})$ & $133.0(\mathrm{~s})$ & $\mathrm{C}-5$ & $1.29(\mathrm{~m})$ & $30.6(t)$ & $30.6(t)$ \\
\hline $\mathrm{C}-2^{\prime}, 6^{\prime}$ & $7.12(\mathrm{~d} ; 8.6)$ & $129.6(\mathrm{~d})$ & $129.6(d)$ & C-6 & $1.26(\mathrm{~m})$ & $30.8(t)$ & $30.8(\mathrm{t})$ \\
\hline $\mathrm{C}-3^{\prime}, 5^{\prime}$ & $6.74(\mathrm{~d} ; 8.6)$ & $116.2(\mathrm{~d})$ & $116.2(\mathrm{~d})$ & $\mathrm{C}-7$ & $1.28(\mathrm{~m})$ & $31.2(\mathrm{t})$ & $31.18(\mathrm{t})$ \\
\hline $\mathrm{C}-4^{\prime}$ & - & $158.5(\mathrm{~s})$ & $158.5(\mathrm{~s})$ & C-8 & $1.06(\mathrm{~m})$ & $28.1(t)$ & $28.1(\mathrm{t})$ \\
\hline \multicolumn{4}{|c|}{ 3-Hydroxyglutamine (3-OHGln) } & C-9 & $1.30(\mathrm{~m})$ & $38.1(\mathrm{t})$ & $38.1(\mathrm{t})$ \\
\hline $\mathrm{C}-1$ & - & $169.4(s)$ & $169.1(\mathrm{~s})$ & $\mathrm{C}-10$ & $1.48(\mathrm{~m})$ & $31.3(\mathrm{~d})$ & $31.24(\mathrm{~d})$ \\
\hline $\mathrm{C}-2$ & $5.05(\mathrm{~d} ; 4.5)$ & $55.3(\mathrm{~d})$ & $55.6(\mathrm{~d})$ & $\mathrm{C}-11$ & 1.23 (ddd; 13.5, 6.7, & $45.9(\mathrm{t})$ & $45.9(t)$ \\
\hline $\mathrm{C}-3$ & 4.32 (ddd; $9.5,3.7$ & $70.8(d)$ & 70.7 (d) & & 0.91 (ddd; $13.5,6.8$ & & \\
\hline $\mathrm{C}-4$ & $\begin{array}{l}2.81(\mathrm{dd} ; 15.5,3.4) \\
2.48(\mathrm{dd} ; 15.5,9.7)\end{array}$ & $39.3(\mathrm{t})$ & $39.4(t)$ & $\mathrm{C}-12$ & $1.39(\mathrm{~m})$ & $32.9(\mathrm{~d})$ & $32.9(\mathrm{~d})$ \\
\hline C-5 & - & $177.2(\mathrm{~s})$ & $177.2(\mathrm{~s})$ & C-13 & $1.08(\mathrm{~m})$ & $30.34(t)$ & $30.34(\mathrm{t})$ \\
\hline \multicolumn{4}{|c|}{ 3,4-Dihydroxyproline (DiOHPro) (9)/ } & C-14 & $0.87(\mathrm{t} ; 7.4)$ & $11.6(q)$ & $11.6(\mathrm{q})$ \\
\hline \multicolumn{4}{|c|}{ 3-Hydroxyproline (3-OHPro) (6) } & C-15 & $0.85(d ; 6.6)$ & $20.7(q)$ & $20.7(q)$ \\
\hline $\mathrm{C}-1$ & - & $173.2(\mathrm{~s})$ & $172.9(\mathrm{~s})$ & C-16 & $0.85(\dot{a} ; 6.6)$ & $20.2(q)$ & $20.2(q)$ \\
\hline $\mathrm{C}-2$ & $4.24(\mathrm{~m})$ & $66.1(\mathrm{~d})$ & $69.8(\mathrm{~d})$ & \multicolumn{4}{|c|}{ Threonine (Thr) } \\
\hline C-3 & $4.18(\mathrm{dd} ; 6.8,3.9)$ & 75.9 (d) & 74.3 (d) & C-1 & - & $172.6(\mathrm{~s})$ & $172.7(s)$ \\
\hline C-4 & $4.23(\mathrm{~m})$ & $71.9(\mathrm{~d})$ & $34.8(\mathrm{t})$ & $\mathrm{C}-2$ & $4.97(\mathrm{~d} ; 3.4)$ & $58.3(\mathrm{~d})$ & $58.3(\mathrm{~d})$ \\
\hline \multirow[t]{2}{*}{ C-5 } & $3.97(\mathrm{dd} ; 11.3,4.1)$ & $54.4(t)$ & $47.0(\mathrm{t})$ & $\mathrm{C}-3$ & $4.55(\mathrm{~m})$ & $68.2(\mathrm{~d})$ & 68.2 (d) \\
\hline & $3.67(\mathrm{dd} ; 11.3,2.5)$ & & & C-4 & $1.16(\mathrm{brd} ; 6.2)$ & $19.7(q)$ & $19.7(q)$ \\
\hline \multicolumn{4}{|c|}{ 4,5-Dihydroxyornithine (DiOHOrn) } & \multicolumn{4}{|c|}{ 4-Hydroxyproline (4-OHPro) } \\
\hline $\mathrm{C}-1$ & - & $174.6(s)$ & $174.5(\mathrm{~s})$ & $\mathrm{C}-1$ & - & $173.4(\mathrm{~s})$ & $173.4(\mathrm{~s})$ \\
\hline $\mathrm{C}-2$ & $4.49(\mathrm{dd} ; 11.2,6.2)$ & $51.3(\mathrm{~d})$ & $51.4(\mathrm{~d})$ & $\mathrm{C}-2$ & $4.55(\mathrm{~m})$ & $62.5(\mathrm{~d})$ & $62.5(\mathrm{~d})$ \\
\hline C-3 & $2.01(\mathrm{~m})$ & $34.9(t)$ & $34.5(t)$ & $\mathrm{C}-3$ & 2.42 (br dd; 13.5, & $38.5(\mathrm{t})$ & $38.5(\mathfrak{t})$ \\
\hline $\mathrm{C}-4$ & $\begin{array}{l}4.01(\mathrm{ddd} ; 9.0,7.1, \\
2.6)\end{array}$ & $70.6(d)$ & $70.6(d)$ & & $\begin{array}{c}7.2) \\
2.03(\mathrm{~m})\end{array}$ & & \\
\hline \multirow[t]{2}{*}{$\mathrm{C}-5$} & $5.33(\mathrm{~d} ; 2.6)$ & $73.8(d)$ & 73.9 (d) & C-4 & $4.54(\mathrm{~m})$ & $71.3(\mathrm{~d})$ & $71.3(\mathrm{~d})$ \\
\hline & & & & C-5 & $\begin{array}{l}3.93(\mathrm{dd} ; 11.1,3.2), \\
3.78(\mathrm{brd} ; 11.1)\end{array}$ & $57.1(\mathrm{t})$ & $57.1(\mathrm{t})$ \\
\hline
\end{tabular}

a Chemical shifts in $\delta$ ppm downfield of TMS. Abbreviation: s, singlet; d, doublet; t, triplet; q, quartet; br, broad; m, multiplet.

b The data for pneumocandin $\mathrm{B}_{0}$ is taken from ref 10 ).

analysis of NMR data. Double quantum filtered-COSY (DQF-COSY) ${ }^{20)}$ and TOCSY (Total correlation spectrosopy $)^{21)}$ spectra connected the protons belonging to the individual residue spin systems; analysis of these spectra was facilitated by analysis of the HMQC $\left({ }^{1} \mathrm{H}\right.$-detected heteronuclear multiple-quantum coherence) spectrum, which permitted the distinction between many of the overlapping methine and methylene proton resonances.

The sequence of the six amino acid residues and the position of attachment of the fatty acid chain was determined by a combination of one- and two-dimensional long range carbon-proton correlation experiments. Analysis of two different $\mathrm{HMBC}$ experiments, one optimized for $J_{\mathrm{C}-\mathrm{H}}=7 \mathrm{~Hz}$ and the other for $J_{\mathrm{C}-\mathrm{H}}=4 \mathrm{~Hz}$, placed: a) the DiOHTyr residue between the 3-OHGin and 4-OHPro residues and b) the DiOHOrn residue between the Thr and DiOHPro residues (Fig. 3). These experiments also established that the dimethylmyristate side chain was attached to the cyclic peptide via an amide linkage between its 
Fig. 3. Selected HMBC correlations observed for pneumocandin $\mathrm{D}_{0}(\mathbf{9})$.
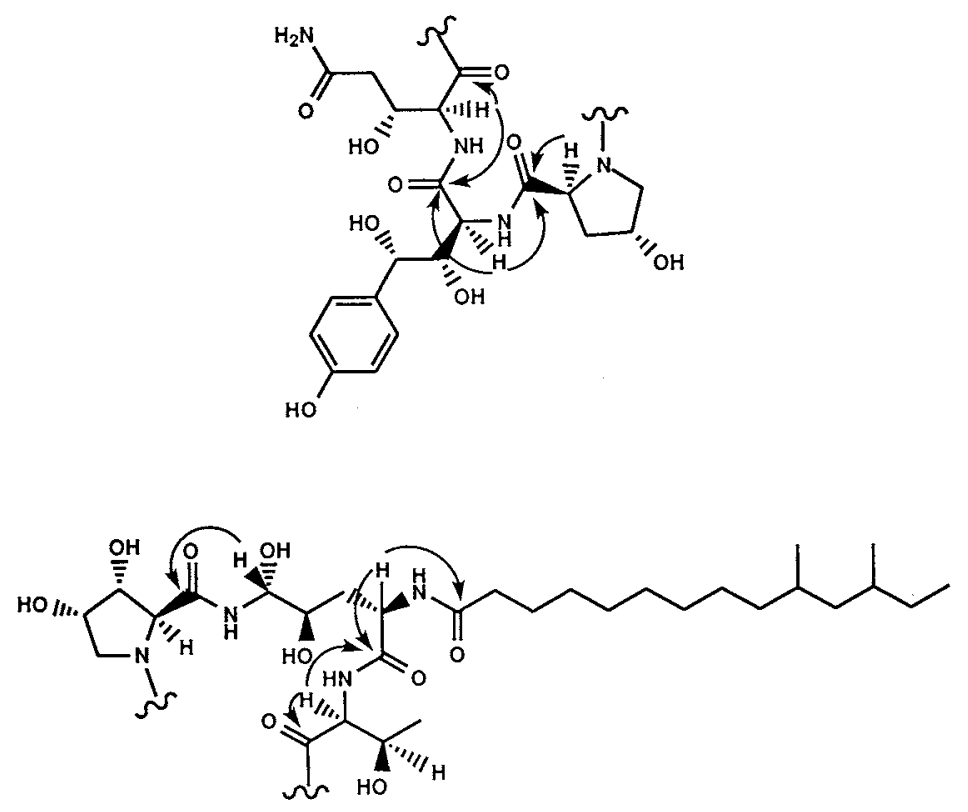

Fig. 4. SIMBA correlations observed in pneumocandin $D_{0}(9)$. $(*$ : carbonyl shift $=169.4 \mathrm{ppm})$

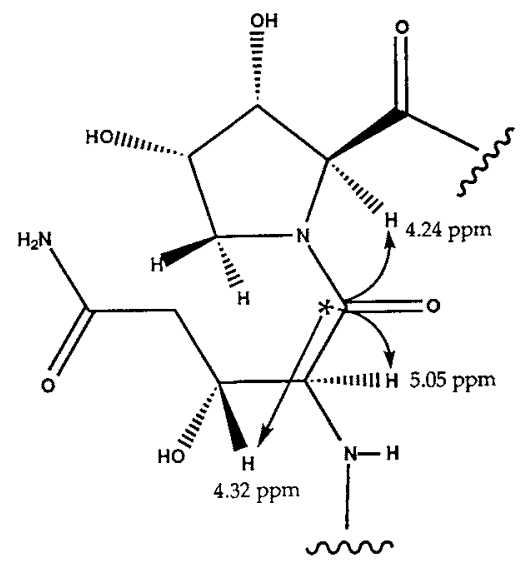

Fig. 5. Selected ROESY correlations observed in pneumocandin $\mathrm{D}_{0}(\mathbf{9})$.

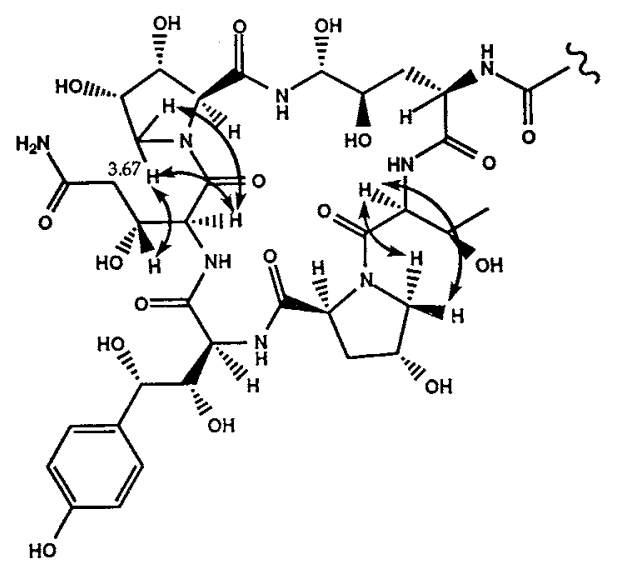

carboxyl group and the $\alpha$-amino group of DiOHOrn, as in all previously isolated pneumocandins. The HMBC experiments did not, however, provide conclusive evidence for the complete sequence of amino acid residues in the cyclic peptide, since no correlations were observed which linked the two halves of peptide, shown in Fig. 3, together. Specifically, no correlations between either DiOHPro and 3-OHGln or 4-OHPro and Thr were evident in the HMBC spectra. Joining of the two halves of the cyclic peptide depicted in Fig. 3 was accomplished by the use of a one-dimensional HMBC (SIMBA) ${ }^{15)}$ experiment. Application of a soft gaussian excitation pulse to the carbonyl resonance at $169.4 \mathrm{ppm}$ (C1 of 3-OHGIn), which is far enough removed $(>3 \mathrm{ppm})$ from neighbouring signals to not cause erroneous excitation, led to clear enhancements of proton signals at 5.05, 4.32 and $4.24 \mathrm{ppm}$ (Fig. 4). The enhanced signals at 5.05 
and $4.32 \mathrm{ppm}$ are associated with $\mathrm{H} 2$ and $\mathrm{H} 3$ of $3-\mathrm{OHGin}$; the signal observed at $4.24 \mathrm{ppm}$ is due to the $\alpha$-proton of DiOHPro. The clearest result was that obtained when $J_{\mathrm{C}-\mathrm{H}}$ was optimized for $4 \mathrm{~Hz}$. This result unequivocally placed the DiOHPro residue between the 3-OHGln and DiOHOrn residues. Further substantiation of this placement came from analysis of the ROESY spectra run on 9. Correlations clearly positioning the two proline residues as depicted in the structure assigned to pneumocandin $D_{0}$ were observed (Fig. 5).

The cis relationship between the two hydroxyls on the diOHPro residue was established based upon the large coupling constant between $\mathrm{H}-3$ and $\mathrm{H}-4(6.8 \mathrm{~Hz})$. The coupling constant between $\mathrm{H}-2$ and $\mathrm{H}-3$ of the diOHPro residue $(3.9 \mathrm{~Hz})$ is consistent with a trans relationship between these two protons; a trans relationship between $\mathrm{H}-2$ and $\mathrm{H}-3$ in the 3-OHPro residue in pneumocandin $\mathrm{B}_{0}$ (coupling constant $3.4 \mathrm{~Hz}$ ) has been unequivocally determined by X-ray crystallography. ${ }^{12)}$ The relative sterochemistries of the other amino acid residues in 9 were assigned to be the same as those in pneumocandin $B_{0}(6)$, since the ${ }^{13} \mathrm{C}$ NMR data for the two compounds are virtually identical. The absolute stereochemistry of 9 was determined by HPLC analysis of the $(R)$ - $\alpha$-methylbenzylisothiocyanate derivatives of the total acid hydrolysate of $\mathrm{D}_{0}$, indicating the presence of $\mathrm{L}$-threonine. Thus, the structure assigned to pneumocandin $\mathrm{D}_{0}$ is that depicted in Fig. 2. Pneumocandin $D_{0}$ is the first reported member of the echinocandin family of antibiotics to possess a 3,4-dihydroxyproline moiety.

Biological Evaluation

Pneumocandin $\mathrm{D}_{0}$ is four times more potent than the previously most potent member of the naturally-occuring pneumocandins, $\mathrm{B}_{0}(6)$, in in vivo efficacy tests against $P$. carinii. However, in the TOKA assay, which measures in vivo efficacy against C. albicans, pneumocandin $\mathrm{D}_{0}$ is nearly equivalent in potency to pneumocandin $A_{0}$, but approximately five times less potent than pneumocandin $B_{0}$ (Table 2). This result is consistent with the general finding that within the pneumocandin class of antifungals, there is a divergence in activity against $P$. carinii
Table 2. PCP, TOKA and MLC results for the pneumocandins. ${ }^{\mathrm{a}}$

\begin{tabular}{lccc}
\hline Compound & $\begin{array}{c}\text { PCP } \\
\mathrm{ED}_{90} \\
(\mathrm{mg} / \mathrm{kg})\end{array}$ & $\begin{array}{c}\text { TOKA } \\
\mathrm{ED}_{90} \\
(\mathrm{mg} / \mathrm{kg})\end{array}$ & $\begin{array}{c}\text { MLC }(\mu \mathrm{g} / \mathrm{ml}) \\
\operatorname{man} / \mathrm{mouse}\end{array}$ \\
\hline Pneumocandin $\mathrm{A}_{0}(\mathbf{1})$ & 0.25 & 1.15 & $>400 />400$ \\
Pneumocandin $\mathrm{A}_{2}(\mathbf{3})$ & $<1.25$ & $>6.00$ & $400 / 400$ \\
Pneumocandin $\mathrm{A}_{4}(\mathbf{5})$ & $>2.50$ & $>6.00$ & $>400 />400$ \\
Pneumocandin $\mathrm{B}_{0}(\mathbf{6})$ & 0.15 & 0.35 & $>400 />400$ \\
Pneumocandin $\mathrm{B}_{2}(\mathbf{7})$ & 0.60 & $>6.00$ & $>400 />400$ \\
Pneumocandin $\mathrm{C}_{0}(\mathbf{8})$ & 0.30 & $>6.00$ & $200 / 200$ \\
Pneumocandin $\mathrm{D}_{0}(\mathbf{9})$ & 0.04 & 1.9 & $>400 />400$ \\
\hline
\end{tabular}

a PCP is the in vivo pneumocystis carinii pneumonia assay, TOKA is the target organ kidney assay for C. albicans in vivo and MLC is the minimum lytic concentration with human or mouse erythrocytes.

Table 3. Anticandida minimal fungicidal concentrations (MFC's; $\mu \mathrm{g} / \mathrm{m} 1$ ) and $1,3-\beta$-D-glucan synthesis $\mathrm{IC}_{50}$ 's for the pneumocandins and related analogs. The particular strain of each species of Candida is listed below the species name.

\begin{tabular}{|c|c|c|c|c|c|c|}
\hline \multirow{2}{*}{ Compound } & \multicolumn{3}{|c|}{ Candida albicans } & \multirow{2}{*}{$\begin{array}{l}\text { C. tropicalis } \\
\text { MY } 1012\end{array}$} & \multirow{2}{*}{$\frac{\text { C. parapsilosis }}{\text { MY } 1010}$} & \multirow{2}{*}{$\begin{array}{c}1,3-\beta \text {-D-glucan } \\
\text { synthesis } \\
\mathrm{IC}_{50}(\mu \mathrm{g} / \mathrm{ml})\end{array}$} \\
\hline & MY 1055 & MY 1028 & MY 1750 & & & \\
\hline Pneumocandin $\mathrm{A}_{0}(\mathbf{1})$ & 0.125 & 0.5 & 0.125 & 0.5 & 2.0 & 0.20 \\
\hline Pneumocandin $\mathrm{A}_{2}(\mathbf{3})$ & 2.0 & 1.0 & 2.0 & 4.0 & 8.0 & 0.20 \\
\hline Preumocandin $\mathrm{A}_{4}$ (5) & 0.5 & 0.5 & 0.5 & 2.0 & 2.0 & 0.30 \\
\hline Pneumocandin $\mathbf{B}_{0}(\mathbf{6})$ & 0.125 & 0.06 & $\mathrm{ND}^{\mathrm{a}}$ & 0.06 & 2.0 & 0.07 \\
\hline Pneumocandin $\mathbf{B}_{2}$ (7) & 1.0 & 1.0 & 16 & 1.0 & 8.0 & ND \\
\hline Pneumocandin $\mathrm{C}_{0}(\mathbf{8})$ & 2.0 & 2.0 & 4.0 & 1.0 & 32.0 & 0.50 \\
\hline Pneumocandin $\mathrm{D}_{0}(\mathbf{9})$ & 1.0 & 0.5 & 1.0 & 2.0 & 8.0 & 0.12 \\
\hline
\end{tabular}

a ND: not determined. 
and $C$. albicans. ${ }^{14)}$ In addition to being tested in the PCP and TOKA assays, pneumocandin $\mathrm{D}_{0}$ was also evaluated in vitro against a panel of clinically relevant pathogenic fungi and in a Candida albicans membrane 1,3- $\beta$-D-glucan synthesis assay. Results from these assays, shown in Table 3 , indicate that pneumcandin $\mathrm{D}_{0}$ is active against a broad spectrum of Candida species, with activity comparable to other members in this antifungal class; in terms of its ability to inhibit $1,3-\beta$-D-glucan synthesis, pneumocandin $B_{0}$ is a slightly more effective inhibitor. The biological data generated for this series of closely related structures allows for the development of structure-activity relationships. To date, pneumocandin $\mathrm{D}_{0}$ is the most active naturally-occurring member of this class of antifungal compounds against $P$. carinii. It is also displays considerable activity against candidiasis in vivo, although two other naturally-occurring pneumocandins,

$A_{0}$ and $B_{0}$, are more potent in this respect.

\section{References}

1) Mizuno, K.; A. Yagi, S. Satoi, M. Takada, M. Hayashi, K. Asano \& T. Matsuda: Studies on aculeacin. I. Isolation and characterization of aculeacin A. J. Antibiotics 30: 297 302, 1977

2) Iwata, K.; Y. Yamamoto, H. YamaGuchi \& T. Hiratani: In vitro studies of aculeacin A, a new antifungal antibiotic. J. Antibiotics 35: $203 \sim 209,1982$

3) Benz, F.; F. Knusel, J. Nuesch, H. Treichler \& W. Voser: Echinocandin B, ein neuartiges Polipeptid-Antibiotikum aus Aspergillus nidulans var. echinatus: Isolierung und Bausteine. Helv. Chim. Acta 57: $2459 \sim 2477,1974$

4) Keller-juslen, C.; M. Kuhn, H. R. Loosli, T. J. Petcher, H. P. Weber \& A. von Wartburg: Structure des Cyclopeptid-Antibiotikum SL 7810 (=Echinocandin B). Tetrahedron Lett. 46: $4147 \sim 4150,1976$

5) TKaCZ, J. S.: Glucan biosynthesis in fungi and its inhibition. In Emerging 'Targets in Antibacterial and Antifungal Chemotherapy. Eds., J. Sutcliffe \& N. H. Georgopapadakou, pp. 495 523, Chapman and Hall, New York, 1992

6) Hammond, M. L.: Chemical and structure-activity studies of the echinocandin lipopeptides. In Cutaneous Antifungal Agents, Selected Compounds in Clinical Practice and Development. Eds., J. W. Rippon \& R. A. FromTling, pp. 395 420, Marcel Dekker, Inc., New York, 1993

7) Schwartz, R. E.; R. A. Giacobbe, J. A. Bland \& R. L. Monaghan: L-671,329, a new antifungal agent. I. Fermentation and isolation. J. Antibiotics 42: $163 \sim 167,1989$

8) Wichmann, C. F.; J. M. Liesch \& R. E. Schwartz: L-671, 329, a new antifungal agent. II. Structure determination. J. Antibiotics 42: $168 \sim 173,1989$

9) Fromtling, R. A. \& G. K. Abruzzo: L-671,329, a new antifungal agent. III. In vitro activity, toxicity and efficacy in comparison to aculeacin. J. Antibiotics 42: 174 178, 1989

10) Schwartz, R. E.; D. F. Sesin, H. Joshua, K. E. Wilson, A. J. Kempf, K. A. Goklen, D. Kuehner, P. Gailliot, C. Gleason, R. White, E. Inamine, G. Bills, P. Salmon \& L. Zitano: Pneumocandins from Zalerion arboricola. I. Discovery and isolation. J. Antibiotics 45: 1853 1866, 1992

11) Masurekar, P. S.; J. M. Fountoulakis, T. C. Hallada, M. S. Sosa \& L. Kaplan: Pneumocandins from Zalerion arboricola. II. Modification of product spectrum by mutation and medium manipulation. J. Antibiotics 45 : $1867 \sim 1874,1992$

12) Hensens, O. D.; J. M. Liesch, D. L. Zink, J. L. Smith, C. F. Wichmann \& R. E. Schwartz: Pneumocandins from Zalerion arboricola III. Structure elucidation. J. Antibiotics 45: 1875 1885, 1992

13) Schmatz, D. M.; M. A. Romancheck, L. A. Pitarelli, R. E. Schwartz, A. Fromtling, K. H. Nollstadt, F. L. VAnmiddesworth, K. E. Wilson \& M. J. TuRner: Treatment of pneumocystis carinii pneumonia with 1,3 $\beta$-glucan synthesis inhibitors. Proc. Natl. Acad. Sci. U.S.A. 87: 5950 5954, 1990

14) Schmatz, D. M.; G. Abruzzo, M. A. Powles, D. C. McFadden, J. M. Balkovec, R. M. Black, K. Nollstadt \& K. BARTizal: Pneumocandins from Zalerion arboricola. IV. Biological evaluation of natural and semisynthetic pneumocandins for activity against Pneumocystis carinii and Candida species. J. Antibiotics 45: 1886 1891, 1992

15) Crouch, R. C. \& G. E. Martin: Selective inverse multiple bond analysis. A simple 1D experiment for the measurement of long-range heteronuclear coupling constants. J. Mag. Res. 92: 189 194, 1991

16) Bidlingmeyer, B. A.; S. A. COHEN \& T. L. TARVIN: Rapid analysis of amino acids sing pre-column derivatization. J. Chromatogr. 336: $93 \sim 104,1984$

17) Bartizal, K.; G. Abruzzo, C. Trainor, D. Krupa, K. Nollstadt, D. Schmatz, R. Schwartz, M. Hammond, J. BALKOVEC \& F. VANMIDDLESWORTH: In vitro antifungal activity and in vivo efficacy of $1,3-\beta$-D-glucan synthesis inhibitors L-671,329, L-646,991, tetrahydroechinocandin B and L-687,781, a papulacandin. Antimicrob. Agents Chemother. 36: $1648 \sim 1657,1992$ 
18) TAFT, C.; T. STARK \& C. P. SelitrennikofF: Cilofungin (LY121019) inhibits Candida albicans $\beta$-1,3-glucan synthase. Antimicrob. Agents Chemother. 32: $1901 \sim 1903,1988$

19) Cabib, E. \& M. S. Kang: Fungal 1,3- $\beta$-glucan synthase. Methods Enzymol. 138: 637 642, 1987

20) Piantini, U.; O. W. Sorensen \& R. R. ERnst: Multiple quantum filters for elucidating NMR coupling networks. J. Am. Chem. Soc. 104: 6800 6801, 1982

21) BAX, A. \& D. G. Davis: MLEV-17-based two-dimensional homonuclear magnetization transfer spectroscopy. J. Magn. Res. 65: 355 360, 1985 